\title{
Internal Seed Structure of Alpine Plants and Extreme Cold Exposure
}

\author{
Ganesh K. Jaganathan ${ }^{1}(\mathbb{D})$ and Sarah E. Dalrymple ${ }^{2, *(\mathbb{D}}$ \\ 1 Institute of Biothermal Technology, University of Shanghai for Science and Technology, \\ Shanghai 20009, China \\ 2 School of Natural Sciences \& Psychology, Liverpool John Moores University, Liverpool L3 3AF, UK \\ * Correspondence: s.e.dalrymple@ljmu.ac.uk
}

Received: 30 June 2019; Accepted: 22 July 2019; Published: 24 July 2019

\begin{abstract}
Cold tolerance in seeds is not well understood compared to mechanisms in aboveground plant tissue but is crucial to understanding how plant populations persist in extreme cold conditions. Counter-intuitively, the ability of seeds to survive extreme cold may become more important in the future due to climate change projections. This is due to the loss of the insulating snow bed resulting in the actual temperatures experienced at soil surface level being much colder than without snow cover. Seed survival in extremely low temperatures is conferred by mechanisms that can be divided into freezing avoidance and freezing tolerance depending on the location of ice crystal formation within the seed. We present a dataset of alpine angiosperm species with seed mass and seed structure defined as endospermic and non-endospermic. This is presented alongside the locations of temperature minima per species which can be used to examine the extent to which different seed structures are associated with snow cover. We hope that the dataset can be used by others to demonstrate if certain seed structures and sizes are associated with snow cover, and if so, would they be negatively impacted by the loss of snow resulting from climate change.
\end{abstract}

Dataset: Submitted as Supplementary Materials to this manuscript.

Dataset License: CC-BY

Keywords: endosperm; intracellular ice formation; climate change; temperature minima; seed mass; snow bed

\section{Summary}

Alpine ecosystems encompass approximately $10 \%$ of the global landscape and harbor about 10,000 plant species. Temperature is a major environmental factor limiting the altitudinal and latitudinal distribution of plants $[1,2]$. With increasing altitude, temperature decreases by $5-10{ }^{\circ} \mathrm{C} \mathrm{km}^{-1}$, and this is accompanied by a concomitant decline in plant diversity and density $[3,4]$. The severity of weather conditions becomes critical above certain altitudes, such that tree growth is limited and these high-altitude mountain slopes give way only to long-lived dwarf herbaceous perennials and very few annuals [3,5]. This tree-less landscape, termed 'alpine tundra' supports plant species that are capable of completing their life-cycle in extremely short growing seasons characterized by high variability of duration and uncertainty in weather [3]. The upper boundary of plant growth in alpine landscapes is difficult to define, but in terms of species adaptation it relates to the permafrost areas on mountains where there is no growing season [3].

One of the distinct features of these high-altitude landscapes is the occurrence of low-temperatures of 0 to $-2{ }^{\circ} \mathrm{C}$ on a daily basis, even during the growing season. However, within the growing 
season, diurnal temperature can fluctuate between the optimal range of $10-30{ }^{\circ} \mathrm{C}$ facilitating rapid plant development, and occasional nocturnal temperatures below $-15^{\circ} \mathrm{C}[3,6,7]$. During the winter, most alpine landscapes remain permanently frozen with air temperatures as low as $-40{ }^{\circ} \mathrm{C}$ [8]. Therefore, plants endemic to high-altitudes are required to tolerate sub-zero temperatures and have adaptations to enable survival in these harsh conditions.

Alpine plant coping strategies include the evolution of freezing tolerance mechanisms in various plant parts, including xylem vessels, leaves, hardy wood tissues, and reproductive structures [9-13]. However, plants have evolved two complex mechanisms to tolerate low temperatures: freezing avoidance by supercooling and freezing tolerance by extracellular freezing, which in turn removes intracellular water through vapor pressure differences [14,15]. Even within a single plant, it is possible that some parts avoid ice formation whilst other tolerate freezing. For example, vegetative organs of alpine cushion plants tolerate ice in the extracellular regions, whereas inflorescences avoid freezing [16].

In contrast to the considerable interest in understanding freezing tolerance in plants $[9,17]$, the mechanisms by which seeds might survive alpine conditions have received far less attention. Seed-set occurs in the autumn for spring germination and dense snow cover during winter provides a thermal buffer for the soil seed bank, thus preventing the seeds from being exposed to the harshest winter temperatures [18]. This benign environment maintains temperatures close to $0{ }^{\circ} \mathrm{C}$ for three to six months, and can facilitate the loss of seed dormancy (cold-stratification), thus widening the temperature requirement for germination and reducing the light dependency of emergence [19].

Most seeds on the soil surface are in an imbibed state late in the winter due to snow melting [7] and the freezing of this internal water becomes the most likely cause of seed death. Water in seeds can, however, supercool to many degrees below the melting point without freezing $[20,21]$ and this constitutes a method of freezing avoidance. The ice formation in supercooled water begins when the temperature is reduced to $-18^{\circ} \mathrm{C}$ and substances in the seed (e.g., bacteria) become the points of heterogeneous ice nucleation. When such nucleation is absent, the freezing of supercooled water is delayed to $-39^{\circ} \mathrm{C}$, a process known as homogenous ice nucleation. Although this latter scenario is possible, heterogenous ice nucleation is more likely because in seeds and other living entities, water does not occur in its pure form and often exists in macromolecular structures [22].

During freezing avoidance, the location of ice formation determines whether viability is lost. Thus, ice in the endosperm and other external structures can be survived, but formation of ice in the intracellular region (IIF), i.e., the embryo, marks the death of seeds $[23,24]$. We hypothesize that the presence of internal seed structures may make a difference to the proximity of ice formation to the embryo, and therefore may affect seed mortality at extremely cold temperatures. A further consideration is that the cooling rate might be important: the occurrence of freezing avoidance is associated with a faster cooling rate (Jaganathan, unpublished).

Although freezing avoidance has been studied in seeds of some species, even rudimental observations of freezing tolerance by freeze desiccation do not exist for seeds. In freezing tolerance, the formation of extracellular ice is tolerated (similar to freezing avoidance), but intracellular ice formation (IIF) is precluded. Unlike freezing avoidance, the formation of extracellular ice in seeds that undergo freezing tolerance decreases the mole fraction and vapor pressure of the extracellular water and when lowered sufficiently below that of the intracellular water, the water present in the embryo is desiccated to extracellular ice [23]. Because the water content of the embryo is reduced below critical level, ice formation in the embryo is prevented at low temperatures.

In alpine systems, the investigation of freezing tolerance might not seem to be a priority research agenda given the predictions for warming temperatures and the expected amelioration of growth constraints. Indeed, alpine plants are predicted to respond negatively to future climate change with implications for species persistence and the plant community composition of montane systems $[25,26]$ meaning that an understanding of freezing tolerance could be dismissed as an academic pursuit. According to Foden et al.'s [27] scheme for identifying species endangered by climate change, alpine plants are at risk due to their specialized microhabitat requirements and rarity, limited dispersal to 
newly-available habitat, and the high likelihood of exceeding physiological tolerances. All of these mechanisms may be contributing to the current loss of alpine species in line with shifting minimum temperature isotherms [28,29], and the predictions for the European Alpine climate suggest that these responses are likely to continue: $3.3^{\circ} \mathrm{C}$ of warming is projected by the end of the 21st century [30]. A specific mechanism of community change may be through the loss of competitive advantage [31]; tolerance to very harsh conditions will become redundant as the warming climate alleviates the selective pressures dictating the vegetation composition at high altitudes. The amelioration of climate subsequently allows species associated with lower altitudes to colonize montane systems.

For seeds in alpine environments specifically, a changing climate is likely to have more complex impacts upon seed survival than those associated purely with the loss of stress-tolerant competitive advantage under warmer conditions. This is because the temperatures experienced at the soil surface are strongly influenced by the presence of snow, and the response of snow is very variable at different temporal and spatial scales. Firstly, warming temperatures will make snow bed cover patchy at smaller spatial scales leading to greater probability of seed dispersing to intolerably cold conditions after short-range dispersal events. For example, seeds dispersed onto wind-blown ridges or other similarly exposed patches may experience soil temperatures lower than $-25^{\circ} \mathrm{C}$ and air temperatures as low as $-30^{\circ} \mathrm{C}[8,32,33]$. Secondly, during the onset of the growing season the risk of seeds being exposed to regular freeze-thaw cycles is increased, as the insulation effect of the snow cover is lost. Such scenarios are expected to prevail in most alpine landscapes and earlier snow-melt in the future means that the seeds are at extreme risk of this [2,34]. Thirdly, even where snow beds persist, climatic warming is expected to reduce the thickness of snow cover and expose the seeds to lower air temperatures [35]. Given these varying impacts, it is imperative that we understand which species might survive and how invasive species respond to climatic changes in order to identify species in need of proactive conservation measures.

We have produced a dataset of seed structure in terms of the presence or absence of an endosperm, seed mass, and the locations in which alpine species experience extremely low temperatures, hereafter referred to as 'temperature minima locations'. We hope that others may utilize the data to investigate the impacts of reduced snow cover by (i) using the temperature minima locations to determine the strength of association of alpine species with snow cover, (ii) integrate these with predictions of snow bed loss, reduced snow thickness and earlier snow melt timings under climate change projections, and (iii) highlight regions where seeds might be at risk of unprecedented exposure to extremely cold temperatures. We also hope that this dataset might facilitate experimental work on the endosperm's role in conferring resilience to extremely low temperatures by extracting ecologically-relevant temperatures at which freezing response can be tested. We predict that the projected loss of snow cover in high altitude regions will result in the exposure of seeds to extremely low temperatures not typically experienced in the evolutionary history of alpine species. We also predict that seed structure and mass will play a part in the ability of the seeds to cope with extreme cold. However, at this moment, we can only link seed structure and mass to the ambient air temperatures interpolated from global climate databases, rather than the soil surface temperatures seeds actually experience, and to really understand if seed traits are linked to survival in extremely cold conditions, we need assistance to incorporate the insulating effects of snow. The dissemination of our dataset will facilitate the collaboration of seed physiologists and those with expertise in the study of climate change and the cryosphere. Describing a link between seed structure, its role in freezing avoidance and/or freezing tolerance, and the impacts of loss of snow bed cover will be an important breakthrough in predicting vegetation response to climate change in high altitude environments.

\section{Data Description}

The data is provided in tabular form entitled "alpine_seed_traits_and_temperature_minima.txt" in the Supplementary Materials File1 appended to this document. Each row constitutes data for a single species with no duplication. The citation for each temperature minima location derived from online 
distributional records is given in a second Supplementary Materials File2 entitled "GBIFcitations.txt" and is provided in several formats as generated by the "rgbif" package (see below for more details on the methods of data extraction and manipulation).

\subsection{Structure of Dataset}

The first column (entitled "Species") lists the species as named in the Global Biodiversity Information Facility (GBIF) 'backbone', i.e., the authorized names recognized in GBIF [36]. The second column lists the key or unique numerical identifier ("GBIF_key") which allows for precise cross-referencing with GBIF occurrence data.

The following three columns are specific to the location at which each species distribution reaches its coldest temperatures according to the Worldclim database of global climatic data [37] and are entitled "country", "decimalLongitude", and "decimalLatitude". The description of how this location was derived is presented in the following section. Figure 1 shows the spread of this location data and is encoded according to the presence of an endosperm in the seeds of each species.

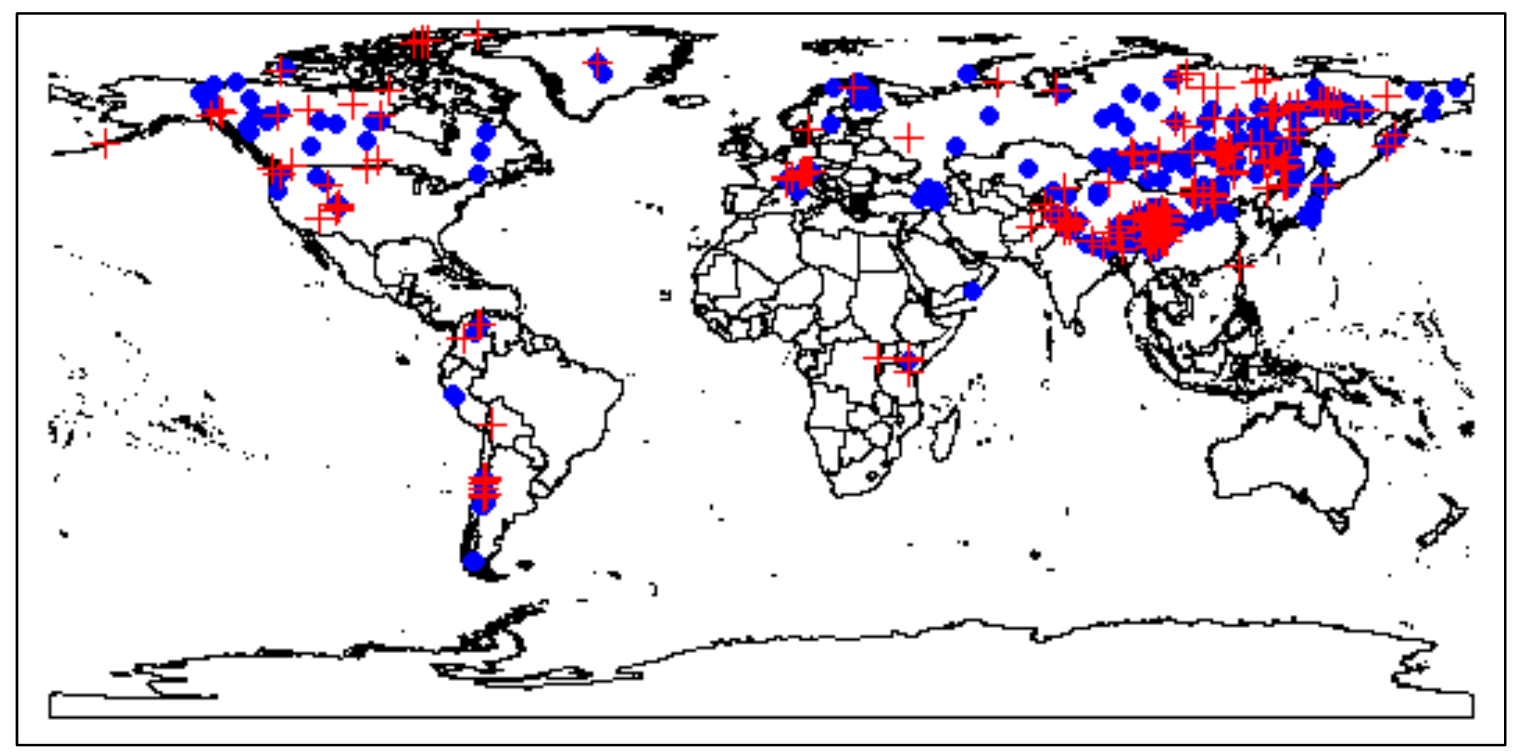

Figure 1. Global distribution of locations at which species attain the coldest temperatures in their respective ranges. Blue circles denote endospermic species occurrences, red crosses denote non-endospermic species occurrences.

The final two columns detail the reported presence of endosperms for each species whereby species are listed as endospermic or non-endospermic (column entitled "seed_structure") and the mass of single seeds are reported in the column entitled "Mean_seed_mass".

\subsection{Descriptive Analyses of Seed Data}

Our dataset contains 840 species known to occur in (but not necessarily restricted to) alpine regions and their status as endospermic (562 species) or non-endospermic (278) with regards to seed structure. Only 285 species have published seed mass data, of which the endospermic seeds are on average $0.116 \mathrm{~g}$ each $(\mathrm{n}=183)$ and the non-endospermic seeds are $0.119 \mathrm{~g}(\mathrm{n}=102)$ with the spread of data after natural log transformation displayed in Figure 2. 


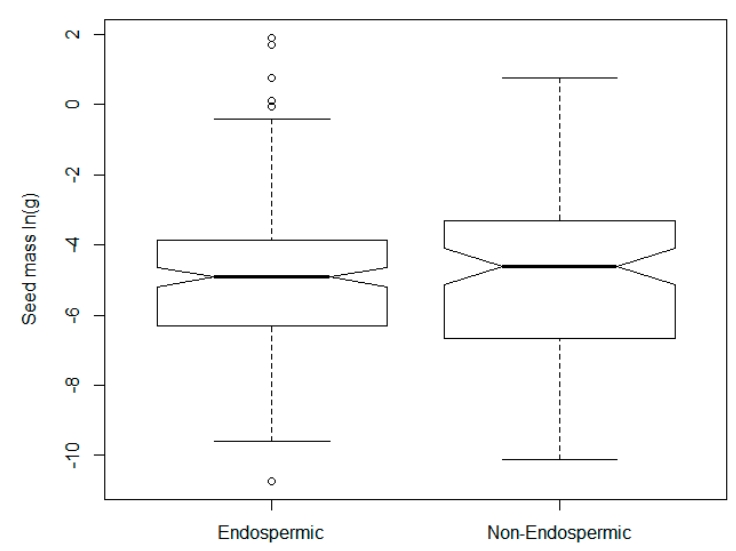

Figure 2. Seed mass (g) after natural log transformation for species with endospermic and nonendospermic seeds.

\subsection{Exploration of Climatic Data Associated with Temperature Minima Locations}

The locations of temperature minima were used to explore climate data downloaded from the Worldclim database and extracted at point locations where each species attained the temperature minima. These climatic variables expressed extreme cold (minimum temperature of the coldest month), or measures of temperature fluctuation that could infer rate and range of temperature change experienced by the seeds (specifically, mean monthly diurnal range, isothermality, temperature seasonality, and temperature annual range; see Section 3 below for fuller description of variables). Our motivation behind these outputs was to see if different measures of extreme cold and temperature fluctuation might be linked to the structure of seeds. If, for example, endospermic seeds were found in colder sites than those at which non-endospermic species were found, it would support our hypothesis that this type of structure conferred a benefit at extremely low temperatures. However, as the following figures show (Figures 3-7) there are no differences in the ambient climate at locations associated with temperature minima between species with and without endospermic seeds. Although apparently uninteresting, we present this data because it highlights our prediction that snow cover will make a substantial difference to temperature minima and temperature fluctuations at relatively small scales. We selected these climatic variables because they encapsulated the absolute minimum temperatures but also, daily, seasonal, and annual variability. Given that we are looking for explanatory mechanisms to enable the prediction of alpine vegetation response, our 'lack of results' serves to highlight our requirement to explore the crucial component of alpine systems which this data cannot convey, i.e., the snow cover.

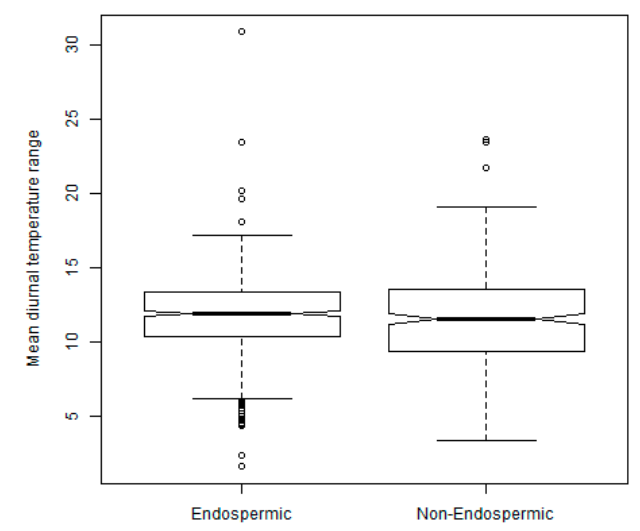

Figure 3. Mean diurnal range (Mean of monthly (max temp-min temp)) at locations where alpine species reach their distributional temperature minima. Data derived from Worldclim [37]. 


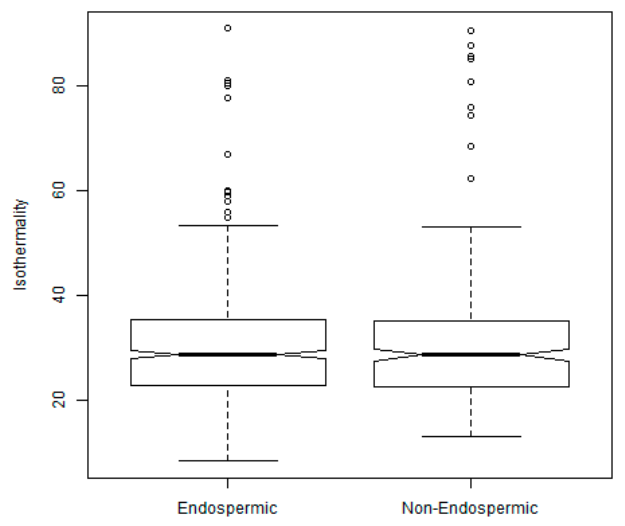

Figure 4. Isothermality at locations where alpine species reach their distributional temperature minima. Data derived from Worldclim [37].

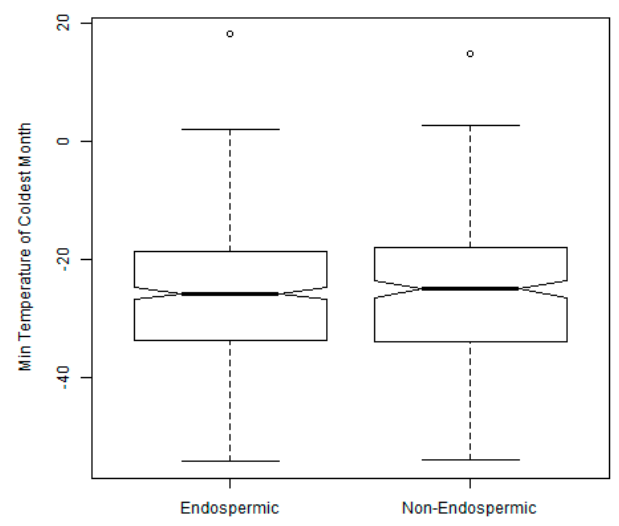

Figure 5. Minimum temperature of the coldest month at locations where alpine species reach their distributional temperature minima. Data derived from Worldclim [37].

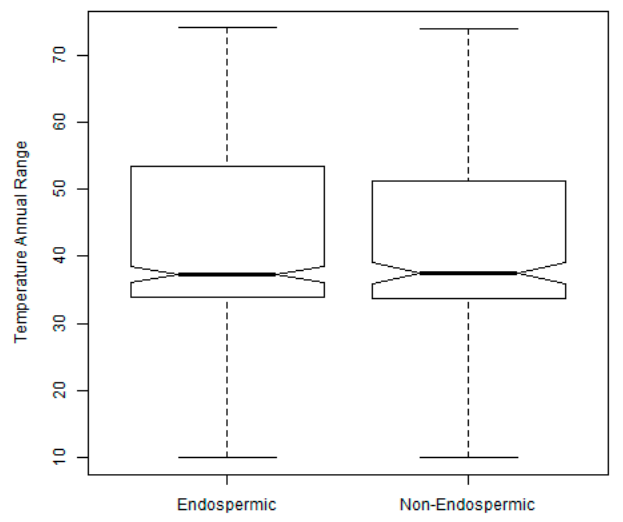

Figure 6. Temperature annual range $\left({ }^{\circ} \mathrm{C}\right)$ at locations where alpine species reach their distributional temperature minima. Data derived from Worldclim [37]. 


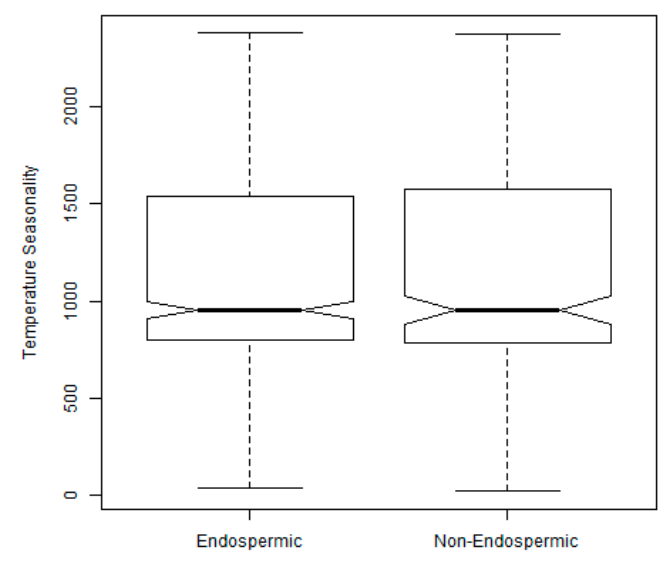

Figure 7. Temperature seasonality at locations where alpine species reach their distributional temperature minima. Data derived from Worldclim [37].

\section{Methods}

We collated data from published literature by searching 'Web of Science' with keywords "alpine plants" and/or "alpine vegetation" to find the plant species occurring in alpine ecosystems. Species were also included from Körner [3] upon consulting the taxonomic index outlined. These inclusions resulted in 2621 species. However, as many species of alpine vegetation reproduce asexually, we checked our database and screened for species that are known to produce seeds either by directly consulting the literature or by contacting the authors of original manuscripts. In the cases where we could not do either of the above, we used online sources such as Kew Seed Information Database and Mabberley's plant book [38].

Seed mass data were either directly sourced from literature, when they are given, or from Kew Seed Information Database. Weight of single seed (averaged) is given. Where seeds were expressed as mass per given number of seeds, we standardized this value to express the mass per seed (g). One limitation of the data is that seed mass is expressed as a single value but whilst some reported values included indicators of variance around the mean, not all authors did so and we have just presented the average seed mass. In addition, seed mass is not available for all species in the dataset.

For the morphology assessment, species or genus was verified based on information given in Martin [39] and Mabberley [38]. In most cases, we consulted both. Seeds with only perisperm were included in the non-endospermic category.

The taxa identified as alpine and for which endosperm presence was derived, contained many obsolete binomials due to more recent taxonomic reclassifications. These were checked for presence and synonyms in the GBIF backbone [36] and updated as necessary. The occurrence data were extracted from GBIF [36] using the package "rgbif" [40] in the R user environment [41] via RStudio [42]. The code for data extraction is available at https://github.com/SarahEDalrymple/seeds_and_cold where the code used at the time of data analysis can be downloaded along with any further refinements (see Section 4 below for further notes on using and adapting this script). A limit on the number of occurrences downloaded was set at 30,000 records in order to provide a pragmatic cut-off that enabled download sizes that were feasible using the available computing resources. This resulted in the omission of 118 taxa from the dataset but given that 840 remained and the limit had the effect of omitting very cosmopolitan species rather than 'true' alpines, this was not perceived to alter the utility of the dataset. Once occurrence records were downloaded for each species, the minimum temperature of the coldest month $\left({ }^{\circ} \mathrm{C}\right)$ was extracted for each occurrence point and the coldest of these singled out to represent the temperature minima location. Following this, a suite of other climatic variables were extracted for the temperature minima location only (Figures 3-7). The data extracted from the Worldclim bioclim dataset [37] cannot be redistributed in its raw form but was used above to highlight the properties of the data at the temperature minima locations as discussed above. These constitute the following variables: 
Minimum temperature of the coldest month ( $\mathrm{t} \_$min), mean monthly diurnal range (diurnal_range), the mean monthly diurnal range divided by the annual temperature range and multiplied by 100 (isothermality), temperature seasonality, or, the standard deviation of mean temperature multiplied by 100 (seasonality), and temperature annual range (annual_range). All reported data derived from temperature in degrees Celsius. The notched boxplots were generated in the R user environment [41] and represent the median (centre line), 95\% confidence intervals (the notch), 25th and 75th percentiles (bottom and top of box, respectively) and minima and maxima (lower and upper ' $\mathrm{T}$ ' bars), with possible outliers displayed as individual points.

The Worldclim data was downloaded at the highest available resolution of 30 arcseconds (approximately $1 \mathrm{~km}^{2}$ ) but this is acknowledged to be quite coarse relative to the scale of the microclimate variation in many alpine regions especially given the influence of microtopography on wind exposure and drainage. However, the minimum ambient temperatures derived from the interpolated Worldclim dataset are likely to be a dependable indicator of extremely low temperatures experienced at these sites, and the impact of adiabatic lapse rate over such areas is not great enough to detract from the overriding patterns in seed freezing tolerance that we identified. There are, of course, many local topographical features that might also change the temperatures experienced by seeds but this reinforces the value of our key finding in light of current attempts to model the impacts of climate change: these large-scale climate patterns can only tell part of the story when it comes to predicting biological losses.

\section{User Notes}

The code available on Github is a complete record of our climate data extraction, GBIF distribution collation and determination of the location at which each species is expected to incur its temperature minima, and can be easily adapted to extract other Worldclim climatic variables at a range of resolutions. The script relies on having a list of species saved as a single column in a text file (ending with ".txt") with which the R package "rgbif" [40] operates to identify occurrences of each of the listed taxa. The code employs a looping function known as a "for" loop in conjunction with an "if-else" conditional statement. The loop takes each taxa in turn and sequentially applies each of the data manipulation steps described above. If our dataset is to be expanded, we recommend that the taxa to be analyzed are thoroughly checked against the GBIF 'backbone', i.e., the taxonomic listings for all GBIF entries. If this is not done, error messages will be generated by unrecognized taxa. Even in cases where the taxonomic name does feature in the GBIF backbone, there are instances of taxa having no validated occurrences in the GBIF dataset and therefore generate a message as follows: "Error: \$ operator is invalid for atomic vectors". Other causes of error messages returned and cessation of progress in the looped script were exclusively due to limitations in Wi-Fi connectivity and bandwidth, and we recommend that future attempts to use our code are only entered into where the internet is reliable and consistently maintains good signal strength.

Supplementary Materials: The following are available online at http://www.mdpi.com/2306-5729/4/3/107/s1, File1: alpine_seed_traits_and_temperature_minima.txt; File2: GBIFcitations.txt.

Author Contributions: Conceptualization, methodology, and writing (all stages), G.K.J. and S.E.D.; data curation, G.K.J.; formal analysis including R code development and visualization, S.E.D.

Funding: This research received no external funding.

Acknowledgments: We acknowledge the assistance of Jan Salanowski in updating the taxonomic records and checking $\mathrm{R}$ code used in data collation and analysis. We kindly thank Hugh Pritchard for his enthusiastic discussion on this subject.

Conflicts of Interest: The authors declare no conflict of interest. 


\section{References}

1. Larcher, W. Bioclimatic Temperatures in the High Alps. In Plants in Alpine Regions: Cell Physiology of Adaption and Survival Stratergies; Lutz, C., Ed.; Springer: Berlin, Germany, 2012; pp. 21-27.

2. Lütz, C. Plants in Alpine Regions: Cell Physiology of Adaption and Survival Strategies; Springer: Berlin, Germany, 2012.

3. Körner, C. Alpine Plant Life: Functional Plant Ecology of High Mountain Ecosystems; Springer: Berlin, Germany, 2003.

4. Körner, C. A re-Assessment of High Elevation Treeline Positions and Their Explanation. Oecologia 1998, 115, 445-459. [CrossRef] [PubMed]

5. Tranquillini, W. Physiological ecology of the alpine timberline. In Tree Existence at High Altitudes with Special Reference to the European Alps; Springer: Berlin, Germany, 1979.

6. Beck, E. Equilibrium freezing of leaf water and extracellular ice formation in Afroalpine 'giant rosette'plants. Planta 1984, 162, 276-282. [CrossRef] [PubMed]

7. Marcante, S. Frost as a limiting factor for recruitment and establishment of early development stages in an alpine glacier foreland? J. Veg. Sci. 2012, 23, 858-868. [CrossRef]

8. Larcher, W.; Kainmüller, C.; Wagner, J. Survival types of high mountain plants under extreme temperatures. Flora-Morphol. Distrib. Funct. Ecol. Plants 2010, 205, 3-18. [CrossRef]

9. Sakai, A.; Larcher, W. Frost Survival of Plants. Responses and Adaptation to Freezing Stress; Springer: Berlin, Germany, 1987.

10. Burke, M. Freezing and injury in plants. Annu. Rev. Plant Physiol. 1976, 27, 507-528. [CrossRef]

11. Squeo, F. Freezing tolerance and avoidance in high tropical Andean plants: Is it equally represented in species with different plant height? Oecologia 1991, 86, 378-382. [CrossRef]

12. Levitt, J. Responses of Plants to Environmental Stress. Chilling, Freezing, and High Temperature Stresses; Academic. Press: New York, NY, USA, 1980.

13. Levitt, J. Responses of Plants to Environmental Stresses. Volume II. Water, Radiation, Salt, and Other Stresses; Academic Press: Cambridge, MA, USA, 1980.

14. Ristic, Z.; Ashworth, E.N. Response of Xylem Ray Parenchyma Cells of Red Osier Dogwood (Cornus sericea L.) to Freezing Stress (Microscopic Evidence of Protoplasm Contraction). Plant Physiol. 1994, 104, 737-746. [CrossRef]

15. Sakai, A. Survival of the twig of woody plants. Nature 1960, 185, 393-394. [CrossRef]

16. Hacker, J. Inflorescences of alpine cushion plants freeze autonomously and may survive subzero temperatures by supercooling. Plant Sci. 2011, 180, 149-156. [CrossRef]

17. Ladinig, U. How endangered is sexual reproduction of high-mountain plants by summer frosts? Frost resistance, frequency of frost events and risk assessment. Oecologia 2013, 171, 1-18. [CrossRef]

18. Williams, R. Patterns of air temperature and accumulation of snow in subalpine heathlands and grasslands on the Bogong High Plains, Victoria. Aust. J. Ecol. 1987, 12, 153-163. [CrossRef]

19. Jaganathan, G.K.; Dalrymple, S.E.; Liu, B. Towards an understanding of factors controlling seed bank composition and longevity in the alpine environment. Bot. Rev. 2015, 81, 70-103. [CrossRef]

20. Lenoir, J. A significant upward shift in plant species optimum elevation during the 20th century. Science 2008, 320, 1768-1771. [CrossRef] [PubMed]

21. Hughes, L. Biological consequences of global warming: Is the signal already apparent? Trends Ecol. Evol. 2000, 15, 56-61. [CrossRef]

22. Foden, W.B. Identifying the world's most climate change vulnerable species: A systematic trait-based assessment of all birds, amphibians and corals. PLoS ONE 2013, 8, 65427. [CrossRef] [PubMed]

23. Parolo, G.; Rossi, G. Upward migration of vascular plants following a climate warming trend in the Alps. Basic Appl. Ecol. 2008, 9, 100-107. [CrossRef]

24. Gworek, J.R.; Vander Wall, S.B.; Brussard, P.F. Changes in biotic interactions and climate determine recruitment of Jeffrey pine along an elevation gradient. For. Ecol. Manag. 2007, 239, 57-68. [CrossRef]

25. Gobiet, A. 21st century climate change in the European Alps-A review. Sci. Total Environ. 2014, 493, 1138-1151. [CrossRef] [PubMed]

26. Björk, R.G.; Molau, U. Ecology of alpine snowbeds and the impact of global change. Arct. Antarct. Alp. Res. 2007, 39, 34-43. [CrossRef] 
27. Bai, Y.; Booth, D.T.; Romo, G.T. Winterfat (Eurotia lanata (Pursh) Moq.) seedbed ecology: Low temperature exotherms and cold hardiness in hydrated seeds as influenced by imbibition temperature. Ann. Bot. 1998, 81, 595-602. [CrossRef]

28. Gusta, L.V.; Gao, Y.P.; Benning, N.T. Freezing and desiccation tolerance of imbibed canola seed. Physiol. Plant. 2006, 127, 237-246. [CrossRef]

29. Mondoni, A. Climate warming could shift the timing of seed germination in alpine plants. Ann. Bot. 2012, 110, 155-164. [CrossRef] [PubMed]

30. Wipf, S.; Rixen, C. A review of snow manipulation experiments in Arctic and alpine tundra ecosystems. Polar Res. 2010, 29, 95-109. [CrossRef]

31. Junttila, O.; Stushnoff, C. Freezing avoidance by deep supercooling in hydrated lettuce seeds. Nature 1977, 269, 325-327. [CrossRef]

32. Bourque, J.E.; Wallner, S.J. Endosperm and pericarp involvement in the supercooling of imbibed lettuce seeds. Plant Physiol. 1982, 70, 1571. [CrossRef] [PubMed]

33. Angell, C.A. Formation of glasses from liquids and biopolymers. Science 1995, 267, 1924-1935. [CrossRef] [PubMed]

34. Keefe, P.; Moore, K. Freeze desiccation: A second mechanism for the survival of hydrated lettuce (Lactuca sativa L.) seed at sub-zero temperatures. Ann. Bot. 1981, 47, 635-645. [CrossRef]

35. Keefe, P.; Moore, K. Freezing Tolerance in Hydrated Lactuca sativa (L) Seed: A Model to Explain Observed Variation Between Seed Lots. Ann. Bot. 1983, 51, 373-383. [CrossRef]

36. GBIF Occurrence Download Accessed from R via rgbif. 2017. Available online: https://github.com/ropensci/ rgbif (accessed on 22 June 2019).

37. Fick, S.E.; Hijmans, R.J. Worldclim 2: New 1-km spatial resolution climate surfaces for global land areas. Int. J. Climatol. 2017, 37, 4302-4315. [CrossRef]

38. Mabberley, D.J. Mabberley's Plant-Book: A Portable Dictionary of Plants, their Classification and Uses; Cambridge University Press: Cambridge, UK, 2008.

39. Martin, A.C. The comparative internal morphology of seeds. Am. Midl. Nat. 1946, 36, 513-660. [CrossRef]

40. Chamberlain, S.; Barve, V.; Mcglinn, D.; Oldoni, D. rgbif: Interface to the Global Biodiversity Information Facility API. R Package Version 1.1.0. 2019. Available online: https://CRAN.R-project.org/package=rgbif (accessed on 29 June 2019).

41. R Core Team. R: A Language and Environment for Statistical Computing; R Foundation for Statistical Computing: Vienna, Austria, 2018.

42. RStudio Team. RStudio: Integrated Development for R Version 1.1.423; RStudio, Inc.: Boston, MA, USA, 2016; Available online: http://www.rstudio.com/ (accessed on 16 February 2018). 